\title{
Inhibition of NF-кB Signaling Pathway by Resveratrol Improves Spinal Cord Injury
}

\author{
Luyao Xu' ${ }^{1}$, Benson O. A. Botchway ${ }^{2}$, Songou Zhang ${ }^{1}$, Jingying Zhou ${ }^{1}$ and Xuehong Liu ${ }^{1 *}$ \\ 'Department of Histology and Embryology, Medical College, Shaoxing University, Shaoxing, China, ${ }^{2}$ Institute \\ of Neuroscience, Zhejiang University School of Medicine, Hangzhou, China
}

Spinal cord injury (SCl) can have a significant impact on an individual's life. Herein, we discuss how resveratrol improves $\mathrm{SCl}$ by inhibiting nuclear factor kappa-lightchain-enhancer of activated $\mathrm{B}$ cells (NF-kB) signaling pathway. Evidences show resveratrol suppresses NF-kB signaling pathway to exert its beneficial effects on various diseases. NF-кB signaling pathway plays a significant role in the pathophysiological mechanisms of $\mathrm{SCl}$ including increase in inflammation, augmentation of damage caused by free radicals and lipid peroxidation as well as facilitation of apoptosis and axonal demyelination. We also discuss mechanisms between resveratrol and NF-кB signaling pathway in the wake of $\mathrm{SCl}$, which can be potential targets for resveratrol to treat $\mathrm{SCl}$.

\section{OPEN ACCESS}

Edited by:

Rodrigo Pacheco,

Fundación Ciencia \& Vida, Chile

Reviewed by:

Zhouguang Wang,

Albert Einstein College of Medicine,

United States

Gregory W. J. Hawryluk,

The University of Utah, United States

*Correspondence:

Xuehong Liu

liuxueh6588@126.com

Specialty section:

This article was submitted to

Neuropharmacology,

a section of the journal

Frontiers in Neuroscience

Received: 03 May 2018

Accepted: 14 September 2018

Published: 04 October 2018

Citation:

Xu L, Botchway BOA, Zhang S,

Zhou J and Liu X (2018) Inhibition

of NF- $\kappa B$ Signaling Pathway by

Resveratrol Improves Spinal Cord Injury. Front. Neurosci. 12:690.

doi: 10.3389/fnins.2018.00690
Keywords: spinal cord injury, resveratrol, NF-кB signaling pathway, inflammation, apoptosis

\section{INTRODUCTION}

Spinal cord injury (SCI) is a severe complication of the spine, leading to severe dysfunction below injured segment. SCI puts pressure on a country's health services whiles also burdening an affected individual's family and society. The International Spinal Cord Society Prevention Committee estimates global-incident rate to be 23 traumatic SCI cases per million (Lee et al., 2014). SCI is categorized into primary injury and secondary injury phases on the basis of its pathophysiology. Although primary injury is transient and can be caused by a mechanical force, it, nevertheless, creates a basic environment for succeeding pathological events. Secondary injury includes a chain of pathological events such as apoptosis, inflammatory response, and excitotoxicity (Silva et al., 2014). SCI can result in different spinal cord dysfunctions and induce complications in other organs such as the lung (Jiang et al., 2016). As primary injury phase is transient, SCI treatment could focus on the secondary injury phase. With that said, there is presently no effective SCI treatment.

Several researches have demonstrated NF- $\mathrm{BB}$ to be a crucial mediator of cellular responses to numerous physiological stimuli. NF-KB signaling pathway has been shown to participate in mediating SCI pathophysiology, subsequently playing a pivotal role in repairing SCI. Inhibition

Abbreviations: Bcl-2, B-cell lymphoma-2; BSCB, blood-spinal cord barrier; COX, cyclooxygenase; ERK, extracellular signal-regulated protein kinase; FAK, focal adhesion kinases; Fn14, fibroblast growth factor-inducible 14; HDAC, histone deacetylase; HSYA, hydroxysafflor yellow A; IKK, IкB kinase; IL, interleukin; JNK, c-Jun N-terminal kinase; miR-372, microRNA-372; MLKL, mixed lineage kinase domain-like; MMP, metalloproteinase; MnSOD, Mn-superoxide dismutase;

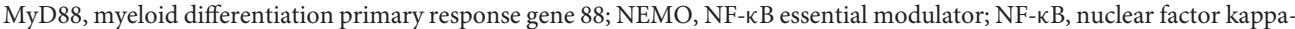
light-chain-enhancer of activated B cells; NIK, NF- $\mathrm{B}$ inducing kinase; NOS, nitric oxide synthase; NPCs, neural precursor cells; NSC, neural stem cell; PI3K, phosphoinositide 3-kinase; RIPK1, receptor-interacting protein kinase 1; ROS, reactive oxygen species; SCI, spinal cord injury; SIRT1, Sirtuin 1; TAK1, TGF-b-activated kinase 1; TGF $\beta$, transforming growth factor- $\beta$; TLRs, Toll-like receptors; TNFR1, tumor necrosis factor receptor 1 ; TWEAK, TNF-like weak inducer of apoptosis. 
of NF- $\mathrm{B}$ by different drugs potentially alleviates SCI (Zhang et al., 2014, 2016; Ni et al., 2015). In view of this, inhibition of NF- $\kappa \mathrm{B}$ could be a potential target for SCI improvement.

Resveratrol, a potent inhibitor of NF- $\kappa \mathrm{B}$, is non-toxic, inexpensive and has multiple pharmacological effects on SCI recovery (Zhao et al., 2017). Resveratrol can modulate cellular growth, autophagy, and immune response by regulating some signaling pathways such as NF-kB, SIRT1, PI3K/Akt/mTOR, ROS/Nrf2/NAF-1, and MAPK pathways (Kulkarni and Cantó, 2015; Chai et al., 2017; Cheng et al., 2018). This review aims to systematically analyze resveratrol's role in regulating NF- $\kappa B$ signaling pathway in the wake of SCI.

\section{PATHOPHYSIOLOGY OF SCI}

Secondary injury phase involves a number of pathophysiological processes including vascular changes such as hemorrhage and breakdown of BSCB, inflammation, peroxidation of lipid membranes and neural cell apoptosis (Silva et al., 2014). Spinal cord edema after SCI induces BSCB opening, leading to release of deleterious substances from blood cells such as neutrophils and macrophages, ultimately resulting in cell death as well as permanent neurological disability (Lee et al., 2012). Inflammatory response is important in SCI development. Inflammation follows immune response, which protects against pathogen. However, excessive inflammation causes damage to body. Major participatory cells of inflammation in SCI include macrophages, endothelial cells, microglia and astrocytes. Classical macrophage (M1) promotes inflammation while alternative macrophage (M2) has a contrasting effect on inflammation. M1 phenotype, activated by Th1 cytokines, LPS-induced signal transducer and activator of transcription 1 signaling, induces pro-inflammatory cytokines (TNF- $\alpha$, IL-1, IL-1 $\beta$, IL- 6 , and IL-12) and nitric oxide, leading to SCI disruption. On the contrary, Th2-induced M2 phenotype promotes anti-inflammatory cytokines (IL-10, TGF$\beta$ ), contributing to attenuation of damage in injured spinal cord (Mantovani et al., 2004). Kopper and Gensel (2017) reported myelin lipid debris, a hallmark of SCI, to be a potent macrophage stimulus. Additionally, it was the target of complement-mediated clearance and inflammation, which was possibly cleared through macrophage surface receptors. Downstream results are determined by myelin-driven events that make macrophages a double-edged sword. Although macrophages are able to promote axonal growth, stem cell differentiation and tissue revascularization to facilitate repair of injured spinal cord, they (i.e., macrophages) can also contribute to SCI pathology through several mechanisms such as release of pro-inflammatory cytokine (Kopper and Gensel, 2017). Inflammation is thought to have an antithetical effect on neuroprotection in SCI. Changing process of different inflammatory factors and cells is different on temporal sequence after CNS trauma (Donnelly and Popovich, 2008). At some point during inflammatory response from destructive to constructive, drugs could improve the pathological process by interfering with inflammatory cells and their released products. In an experimental study of NSC transplantation in SCI, results evinced NSC transplantation to modulate inflammation and enhance neurological function following SCI by reducing M1 macrophages' inflammatory activity and infiltration of neutrophils (Cheng et al., 2016).

Reactive oxygen species (ROS) and oxidative stress are important events that have been associated with SCI. Both neuronal and glia cells in injured spinal cord are sensitive to oxidative and electrophilic stress (Jia et al., 2012). Ketone metabolite, $\beta$-hydroxybutyrate, has been reported to have the capability of inhibiting class I HDACs so as to attenuate oxidative stress in SCI. Selected suppression of either HDAC1 or HDAC2 systematically mediates FOXO3a, NOX2 and NOX4 expressions (Kong et al., 2017). Regarding excitotoxicity, studies have reported glutamate receptors to mediate cell death, which was potentiated by TNF- $\alpha$ (Beattie et al., 2002). All these disparate mechanisms could potentially interact with each other and culminate in axonal demyelination, glial scars and neuronal diminution.

\section{NF- $K B$ SIGNALING PATHWAY FOLLOWING SCI}

Nuclear factor kappa-light-chain-enhancer of activated B cells

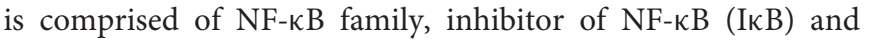

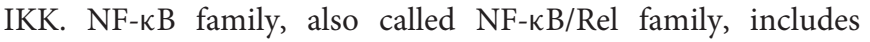
NF-кB1 (p50), NF-кB2 (p52), p65 (RelA), c-Rel and RelB.

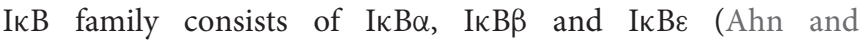
Aggarwal, 2005; Heise et al., 2014). IKK is a large protein complex that modulates phosphorylation of $\kappa \mathrm{B}$ inhibitor. In resting cells, inactive NF- $\mathrm{KB}$ has been associated with inhibitor proteins, I $\mathrm{K} \alpha$, I $\mathrm{\kappa} \beta \beta$, or I $\mathrm{\kappa} B \varepsilon$, masking its nuclear localization sequence and inhibiting its DNA-binding activity (O'Dea et al., 2007). In spinal cord, NF-кB transcription factors are expressed in glial cells and blood vessels, which functions mainly in mediating various mechanisms such as inflammation.

\section{Exhibition of Inflammation}

Inflammatory signs can be detected during acute phase of

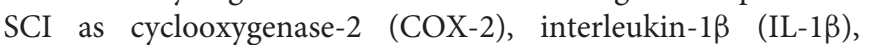
interleukin-6 (IL-6) and interleukin receptors (IL-4R and IL-2Ra) are upregulated from 0.5 to $6 \mathrm{~h}$ following injury. Four main inflammatory cells (neutrophils, monocytes, lymphocytes and microglias) are assembled and release inflammatory cytokines. These pro-inflammatory factors, at low concentration, could trigger inflammation in order to protect normal tissues in spinal cord. When these proinflammatory factors are overexpressed, they tend to activate transcription factors such as NF- $\mathrm{kB}$ that could cause cell death, subsequently altering role of pro-inflammatory factors from positive to negative (Bareyre and Schwab, 2003). Following that, inflammation could create an environment that instigates other pathological events. Among transcription factors that are negative result of inflammation, NF- $\mathrm{B}$ is of great importance. Once stimulated by either inflammatory intercellular signals or other signals like oxidative stresses such as free radicals, 
metabolic stress, or genotoxic stress in SCI, NF- $\mathrm{\kappa B}$ signaling pathway could be induced by "classical" and "alternative" pathways.

In the "classical" pathway, NF- $\kappa \mathrm{B}$ is mediated by activation of a number of cell surface receptors, including TLRs, IL-1 receptor, and TNF receptor. TLRs, a type I transmembrane proteins with extracellular domains, has a close contact relationship with NF- $\kappa$ B. In one of TLR signaling pathway, MyD88-dependent pathway, TLR recruits toll-interleukin 1 receptor domain containing adaptor protein at the cell membrane, facilitating recruitment of MyD88, which in turn could trigger early-phase activation of NF- $\mathrm{KB}$. In another TLR signaling pathway, namely TIR-domain-containing adapter-inducing interferon- $\beta$ (TRIF)dependent pathway, TLR4 forms a signaling complex with TRIFrelated adaptor molecule and TRIF, potentially culminating in late-phase activation of NF- $\mathrm{KB}$, interferon regulatory factor 3 activation and interferon- $\beta$ transcription (Kawai and Akira, 2010). IKK phosphorylates two N-terminal serines of IкB $\alpha$ and IкB $\beta$ leading to poly ubiquitination of ІкBs. Then, ІкBs degrade via $26 \mathrm{~S}$ proteasome that possibly activates NF- $\mathrm{\kappa B}$ (Zandi et al., 1998; O'Dea et al., 2007). Eventually, NF-кB liberated from IкBs enters the nucleus to activate target gene expression, leading to possible differential effect on gene expression.

The "alternative" pathway triggered by activation of TNF-receptor initiates NIK to stimulate IKK $\alpha$-induced phosphorylation and proteolytic processing of cytoplasmic NF- $\kappa$ B2 precursor. Activated NF- $\kappa$ B2, RelB and NIK form a complex to enter the nucleus, potentially activating gene expression. This pathway is mainly involved in immune response (Brasier, 2006). Various pro-inflammatory molecules like TNF- $\alpha$, IL-1, IL- 6 and inducible NOS are mediated by nucleus NF- $\kappa B$ complex, possibly engendering inflammation in spinal cord.

Hydroxysafflor yellow A (HSYA) has anti-inflammatory and anti-oxidative effects on neuronal protection (Zhang et al., 2014). Pei et al. (2017) study evidenced effects of HSYA inhibiting NF- $\kappa B$ activation and curtailing TNF- $\alpha$ and IL- 6 in spinal cord after HSYA treatment, which confirms the vital role of NF- $\kappa \mathrm{B}$ in exhibition of inflammation in SCI. Also, expression of miR-372 is stimulated in cultured human NSCs by IL- $1 \beta$ possibly binding with NF- $\mathrm{KB}$ at its promoter region. Thus, miR372 could potentially be involved in inflammatory signaling mediated by NF-KB (Zhou et al., 2017). Again, TWEAK, Fn14 and NF-KB had a synchronous alteration in a conducted study. Down-regulation of TWEAK curtailed TNF- $\alpha$ and IL- $1 \beta$ expressions. This suggests stimulation of TWEAK-Fn14 pathway might promote NF- $\mathrm{KB}$ expression and possibly culminate in elevated expression level of inflammatory cytokines ( $\mathrm{Xu}$ et al., 2016).

\section{Free Radicals and Lipid Peroxidation}

Free radicals are mainly from endoplasmic reticulum and mitochondria. Reactions between free radicals and polyunsaturated fatty acid of plasma membrane peroxidates and disrupt normal phospholipid structure of cellular biomembrane system (Jamme et al., 1995). NF-кB can be mediated by free radicals. NF- $-\mathrm{B}$ activation is induced by TNF- $\alpha$, IL- $1 \beta$, TLRs, or antigen receptor (TCR, BCR) ligation, which promotes expression of a number of genes (Gloire et al., 2006). These genes, which include mitochondrial MnSOD, are involved in anti-oxidative stress response. MnSOD is an enzyme that inhibits TNF- $\alpha$-induced ROS production and cell death (Kamata et al., 2005). Inhibition of NF- $\mathrm{kB}$ sustains oxidative stress and stimulates either apoptosis or necrosis of cells. In contrast to ROS, induced NOS from different sources like endothelial cells and neurons trigger S-nitrosylation of JNK1 and IKKb protein kinases to impede autophagic flux in mammalian cells. S-nitrosylation of JNK1 stabilizes Beclin 1/Bcell lymphoma-2 (Bcl-2) complexes by reducing phosphorylation of Bcl-2, which can potentially block early steps of formatting autophagic membranes. S-nitrosylation of IKKb has same effect as JNK1 on Adenosine 5'-monophosphate (AMP)-activated protein kinase phosphorylation in suppressing autophagy initiation (Kaminskyy and Zhivotovsky, 2014). NF-кB, c-Fos and c-Jun expressions, as activators of oxidative response markers, suggest possible augmented production of ROS is likely to give rise to cascades of oxidative destruction. Also, lipid peroxidation and nucleic acid oxidation are elevated in injured spinal cord and motor neurons. Consequently, increased degeneration of ROS could contribute to motor neuronal death in spinal cord, which is an early causal event in the wake of SCI (Xu et al., 2005).

\section{Apoptosis and Demyelination of Axons}

Though neuronal damage in SCI occurs predominantly through necrosis, apoptosis cannot be ignored. Intracellular hypercalcemia induced by loss of ionic homeostasis after SCI activates calcium-dependent proteases and results in mitochondria dysfunction, eventually leading to apoptotic cell death (Schanne et al., 1979). Signaling pathways such as Fas/FasL have been evidenced to mediate apoptosis. NF$\kappa \mathrm{B}$ has been reported to be involved in apoptosis. A recent study evinced that during early phase of SCI, TWEAK might assemble pro-inflammatory factors to instigate cell apoptosis through its effect on NF- $\mathrm{B}$ expression (Xu et al., 2016). RIPK1 functions as a node which drives cell survival and inflammation mediated by NF- $\kappa$ B, caspase-8-dependent apoptotic and RIPK3/MLKL-dependent necroptotic cell death (Takahashi et al., 2014). Interplay between IKK/NF- $\kappa B$ and RIPK1 signaling is an important determinant of tissue homeostasis and inflammation. In the intestine and liver, NEMO regulates RIPK1 kinase activity-mediated apoptosis through NF- $\kappa \mathrm{B}$-dependent and independent functions, which are crucial for inhibiting chronic tissue injury and inflammation (Kondylis et al., 2017). A new function of TAK1 was reported to regulate checkpoint of early NF- $\kappa B$-independent cell death in TNFR1 apoptotic pathway. Ub chains conjugated with RIPK1 or other TNFR1 complex I functions as scaffolds in the recruitment and activation of TAK1-binding protein 2/3-TAK1 complex and inhibition of IKK complex (NEMO-IKKa-IKKb), potentially triggering off mitogen-activated protein kinases and classical NF- $\mathrm{B}$ signaling pathways that collectively promotes gene transcription, preventing cell death and sustaining inflammation. Thus, a pro-survival TNFR1 ligation will switch to a pro-apoptotic one when NF- $\mathrm{KB}$ response is potentially 
inhibited (Dondelinger et al., 2013). Besides, ROS is related to apoptosis. A previous study reported ROS generation to be required for TNF-mediated necroptosis (Vanlangenakker et al., 2011). ROS scavenging has the potentiality of inhibiting caspase activation and assembly of complex IIb on TNF stimulation (Dondelinger et al., 2013). Microglia-derived TNF- $\alpha$ was found to induce Puma expression, a member of $\mathrm{BH} 3$-only family in NPCs via an NF- $\kappa \mathrm{B}$-dependent mechanism. More specifically, NF-кB was activated in NPCs cultivated with conditioned media from activated microglia. Also, NF- $\kappa$ B inhibitor, BAY-117082, blocks Puma induction, and NPC apoptosis (Guadagno et al., 2013). There are reports stating taxifolin might possibly reduce neuronal apoptosis induced by cholesterol oxidation product through suppression of cell death mediated by Akt and NF- $\kappa \mathrm{B}$ activation (Kim et al., 2017). In the only contrasting study, neuroprotective effect of neuronal IKK-2 in autoimmune demyelination was reported (Emmanouil et al., 2011). In rats, loss of oligodendrocytes could possibly lead to axonal demyelination and peaks at about $24 \mathrm{~h}$ following injury. Persistent demyelination is related to atrophy and potential death occurring in related cell bodies (Rowland et al., 2008). When demyelination happens in SCI, microglia phagocytizes myelin debris (Blank and Prinz, 2014). Degenerated myelin containing inhibitory molecules like NogoA and Oligodendrocyte-myelin glycoprotein activates FAK/PI3K/Akt/NF- $\kappa$ B pathway in macrophages and promotes expression of inflammatory mediators (Sun et al., 2010). Activated astrocytes and microglia potentially enhances NF- $\mathrm{B}$ activation. However, there are no reports of NF-кB activation in oligodendrocytes. During remyelination, NF- $\kappa \mathrm{B}$ in recruited oligodendrocyte progenitor cells is activated. These progenitor cells, which engage demyelinated axons, are differentiated into remyelinating oligodendrocytes (Blank and Prinz, 2014). A study found E6020 to induce TLR4-dependent cytokine expression such as TNF $\alpha$, IL1 $\beta$, IL- 6 and NF- $\kappa \mathrm{B}$ signaling in vitro. Injection of $\mathrm{E} 6020$ with lysolecithin into rat spinal cord white matter increased axonal sparing, accelerated myelin debris clearance, enhanced Schwann cell infiltration into demyelinated lesions and increased number of remyelinated axons (Church et al., 2017). Taking all these studies into consideration, NF$\kappa \mathrm{B}$ signaling pathway is predominately involved in various pathophysiological mechanisms of SCI, especially with regards to inflammation.

\section{RESVERATROL INHIBITS NF- $\kappa B$ SIGNALING PATHWAY}

Resveratrol (trans-3,5,4-trihydroxystilbene), a small natural polyphenol found in red wine, grapes, peanuts and other different kinds of plant sources is widely studied and used in therapies of different diseases. Resveratrol, used in Indian herbal, traditional Chinese, and Japanese medicine for human health, can be traced back 2000 years ago, with a prime example of a well-known Indian herbal preparation being "darakchasava." Resveratrol is a naturally polyphenolic phytoalexin first identified from Veratrum grandiflorum in 1939 (Takaoka, 1939) and later detected in dried roots of Polygonum cuspidatum, in the leaf epidermis and skin of grape berries. Resveratrol was initially applied to treat injuries (Langcake and Pryce, 1976). Cardiovascular effect of red wine was called "the French paradox," with resveratrol attracting widespread attention in the early 1990s (Renaud and de Lorgeril, 1992). Wood et al. (2004) initially reported resveratrol to extend lifespan in yeast and in worms. Since then, numerous beneficial effects of resveratrol have been reported in different pathological conditions, experimental models and clinical studies. A growing body of evidence shows resveratrol might play potential therapeutic roles in cardiovascular disease, cancer, ischemic injury, sarcopenia, diabetes, obesity, respiratory diseases, osteoarthritis and neurodegeneration (Table 1). It has various pharmacological effects such as anti-oxidative, anti-inflammation, cardiovascular protection, anti-diabetic, restoration of immune system function (Lai et al., 2017), antiapoptosis (Huang et al., 2014), anti-nociception (Pan et al., 2016), anti-depression (Finnell et al., 2016), anti-cancer activities (Chin et al., 2015; Kumar et al., 2015), neuronal protection (Nalagoni and Karnati, 2016) and regulation of metabolism (Luo et al., 2017). Biological activity of resveratrol can possibly be achieved by mediating NF- $\kappa \mathrm{B}$ (Tsang et al., 2016), heme oxygenase-1 (HO-1) (Sakata et al., 2010), mitogen-activated protein kinase (MAPK) (Ma et al., 2015), endothelial nitric oxide synthase (eNOS) (Xia et al., 2010), nuclear factor E2related factor-2 (Nfr2) (Cheng et al., 2018), estrogen receptor (ER) (Saluzzo et al., 2016) and HDAC SIRT1 (Chai et al., 2017). Based on enumerated effects, there are reports positing resveratrol could potentially be employed in the treatment of medical conditions such as Alzheimer's disease (Moussa et al., 2017), diabetes, cardiovascular diseases as well prostate and breast cancers (Chin et al., 2015; Kumar et al., 2015; Zare Javid et al., 2017). Resveratrol functions via several signaling pathways, one being NF- $\mathrm{B}$. Accumulating studies indicate inhibition of NF- $\kappa \mathrm{B}$ signaling pathway by resveratrol potentially plays a significant role in various pathological processes (Figure 1).

Reports evidence resveratrol to suppress various cytokines such as TGF $\beta$, MMP, COX-2, TNF- $\alpha$, IL-1 $\beta$, IL- 6 and intercellular cell adhesion molecule-1 (ICAM-1). All these demonstrate the linkage between resveratrol and NF- $\kappa \mathrm{B}$ owing to expression of these cytokines being mediated by NF- $\mathrm{B}$ signaling pathway. In liver diseases, prevention of fibrosis by resveratrol is concomitant with preventing translocation of NF- $\mathrm{B}$ and down-regulating profibrotic cytokine TGF $\beta$ (Chávez et al., 2008). In a rat model of early polymicrobial sepsis-induced acute kidney injury, resveratrol significantly improved tubular epithelial cell injury and renal function, subsequently enhancing rat survival rate. This was concomitant with substantial decrement of TNF- $\alpha$, IL- $1 \beta$ and IL-6 expressions in serum content and renal mRNA (Wang et al., 2017). Resveratrol reduces ICAM-1 expression in attenuation of endothelial inflammation, which is partly mediated through miR-221/222/AMPK/p38/NF-кB pathway (Liu et al., 2017). In human fibroblast-like synoviocytes, resveratrol was reported to inhibit COX-2/PGE expression so as to suppress particulate matter-induced inflammatory signaling pathways (Tsai et al., 2017). Moreover, resveratrol acts on two critical transcription 
TABLE 1 | Summary of beneficial effects of Resveratrol (RES).

\begin{tabular}{|c|c|c|c|c|}
\hline Diseases & Species & Dose & Results & Reference \\
\hline Brain injury & Rat and mouse & 60 or 90 mg/kg & $\begin{array}{l}\text { RES has an efficient neuroprotection against } \\
\text { subarachnoid hemorrhage }\end{array}$ & Zhang et al., 2017 \\
\hline Cardiovascular disease & Rat & $15 \mathrm{mg} / \mathrm{kg}$ & $\begin{array}{l}\text { RES improves left ventricular function and decreases } \\
\text { myocardial hypertrophy, fibrosis, and severity of heart } \\
\text { failure. }\end{array}$ & Riba et al., 2017 \\
\hline Neurodegeneration & Mouse & $10 \mathrm{mg} / \mathrm{kg}$ & $\begin{array}{l}\text { RES significantly attenuates acute neurological deficits, } \\
\text { neurodegeneration and cerebral edema after } \\
\text { intracerebral hemorrhage }\end{array}$ & Bonsack et al., 2017 \\
\hline Sarcopenia & Rat & 125 mg/kg & $\begin{array}{l}\text { RES reduces apoptotic signaling in muscles of old } \\
\text { animals }\end{array}$ & Bennett et al., 2013 \\
\hline Acute pancreatitis & Rat & $10-50 \mathrm{mg} / \mathrm{kg}$ & $\begin{array}{l}\text { RES attenuates pancreatic oxidative damage by } \\
\text { down-regulating NF-кB and PI3K signaling pathways }\end{array}$ & Tsang et al., 2016 \\
\hline Obesity & Mouse & $15 \mathrm{mg} / \mathrm{kg}$ & $\begin{array}{l}\text { RES increases Cidea mRNA level and UCP1 protein } \\
\text { expression }\end{array}$ & Arias et al., 2017 \\
\hline \multirow[t]{3}{*}{ Diabetes } & Mouse & $40 \mathrm{mg} / \mathrm{kg}$ & & \\
\hline & & & & Zhao et al., 2018 \\
\hline & & & $\begin{array}{l}\text { RES attenuates testicular apoptosis in type } 1 \text { diabetic } \\
\text { mice }\end{array}$ & \\
\hline Respiratory diseases & Mouse & $\begin{array}{l}50 \mathrm{mg} / \mathrm{kg} \\
40 \mu \mathrm{g} / \mathrm{ml}\end{array}$ & $\begin{array}{l}\text { RES relieves LPS-induced inhibition on SIRT1 } \\
\text { expression and restrains activation effects of LPS on } \\
\text { MAPKs and NF-KB activation }\end{array}$ & Ma et al., 2015 \\
\hline Kidney injury & Rat & $0.23 \mu \mathrm{g} / \mathrm{kg}$ & $\begin{array}{l}\text { RES inhibits inflammatory responses and improves } \\
\text { renal function after renal Ischemia-reperfusion injury }\end{array}$ & Li et al., 2018 \\
\hline Colorectal cancer & Human & $5 \mu \mathrm{M}$ & RES induces apoptosis, suppresses NF-кB activation & Buhrmann et al., 2018 \\
\hline Thyroid cancer & Rat & $100 \mu \mathrm{M}$ & $\begin{array}{l}\text { RES inhibits NF-кB/p65 signaling, IL-6 and COX-2 } \\
\text { expressions }\end{array}$ & Zheng et al., 2018 \\
\hline Breast cancer & Human & $0-100 \mu \mathrm{M}$ & RES inhibits breast cancer cellular proliferation & Poschner et al., 2018 \\
\hline Pancreatic cancer & Human & $50 \mu \mathrm{M}$ & $\begin{array}{l}\text { RES promotes pancreatic cancer apoptosis through } \\
\text { ROS/Nrf2/NAF-1 pathway }\end{array}$ & Cheng et al., 2018 \\
\hline ovarian cancer & Human & 10,20 , or $30 \mu \mathrm{M}$ & $\begin{array}{l}\text { RES reduces cell growth and metabolism of SKOV-3 } \\
\text { aggregates }\end{array}$ & Tino et al., 2016 \\
\hline Liver cancer & Human & $100 \mu \mathrm{M}$ & RES inhibits PI3K/AKT pathway by SIRT1 activation & Chai et al., 2017 \\
\hline Gastric cancer & Human & $100 \mu \mathrm{M}$ & $\begin{array}{l}\text { RES inhibits growth of MGC- } 803 \text { cells by inhibiting Wnt } \\
\text { signaling pathway }\end{array}$ & Dai et al., 2018 \\
\hline \multirow[t]{3}{*}{ Prostate cancer } & Mouse & $625 \mathrm{mg} / \mathrm{kg}$ & & \\
\hline & & & & Harper et al., 2007 \\
\hline & & & RES suppresses prostate cancer progression & \\
\hline Osteoarthritis & Rat & $50 \mathrm{mg} / \mathrm{kg}$ & $\begin{array}{l}\text { RES reduces inflammatory responses by inhibiting } \\
\text { NF-кB expression }\end{array}$ & Wei et al., 2018 \\
\hline
\end{tabular}

factors to downregulate COX-2 expression: p50/p65 under the control of signaling cascade IKKB $\alpha / \mathrm{I} \kappa \mathrm{B} \alpha$ and activator protein1 complex of MAPK/ERK/p38/JNK (Bhat and Pezzuto, 2002; Kundu et al., 2006; Cianciulli et al., 2012). In ovarian cancer cell aggregates, resveratrol and acetyl-resveratrol potentially inhibits cell growth, which is correlated with decreased secretion of vascular endothelial growth factor and attenuation of NF- $\kappa \mathrm{B}$ (Tino et al., 2016). As an NF- $\kappa \mathrm{B}$ signal transduction inhibitor, resveratrol inhibits MMP-9 and COX-2 so as to prevent disruption of blood brain barrier during neuroinflammation in carcinogen-induced brain endothelial cells (Annabi et al., 2012).

Inhibition of p65 subunit translocation by resveratrol to the nucleus is a mechanism that was deduced from an experimental hepatocarcinogenesis model (Bishayee et al., 2010). Resveratrol decreases I $\mathrm{B}$ phosphorylation as well as phosphorylation, acetylation and translocation of NF- $\mathrm{B}$ p65 induced by TNF$\alpha$ (Liu et al., 2017). Reduction of IкB phosphorylation, p65 protein levels in nucleus and $\mathrm{NF}-\kappa \mathrm{B}$ transcriptional activity by resveratrol is involved in resveratrol-induced apoptosis ( $\mathrm{Li}$ et al., 2013). Resveratrol can potentially regulate levels of NF$\kappa \mathrm{B}$-mediated miRNAs. Resveratrol inhibits miR-21 expression to suppress NF- $\kappa$ B activity (Li et al., 2013). Resveratrol was reported to downregulate miR-21 expression and other comiRs including miR-30a-5p, miR-19 as well as their targeted or related components (Wang et al., 2015). Interestingly, in U251 cells, over-expression of miR-21 reversed resveratrol on NF- $\kappa$ B activity and apoptosis (Li et al., 2013).

Also, resveratrol requires the enzyme, SIRT1, so as to

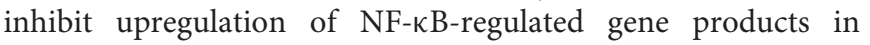
promoting chondrogenic differentiation of mesenchymal stem cells (Buhrmann et al., 2014). 


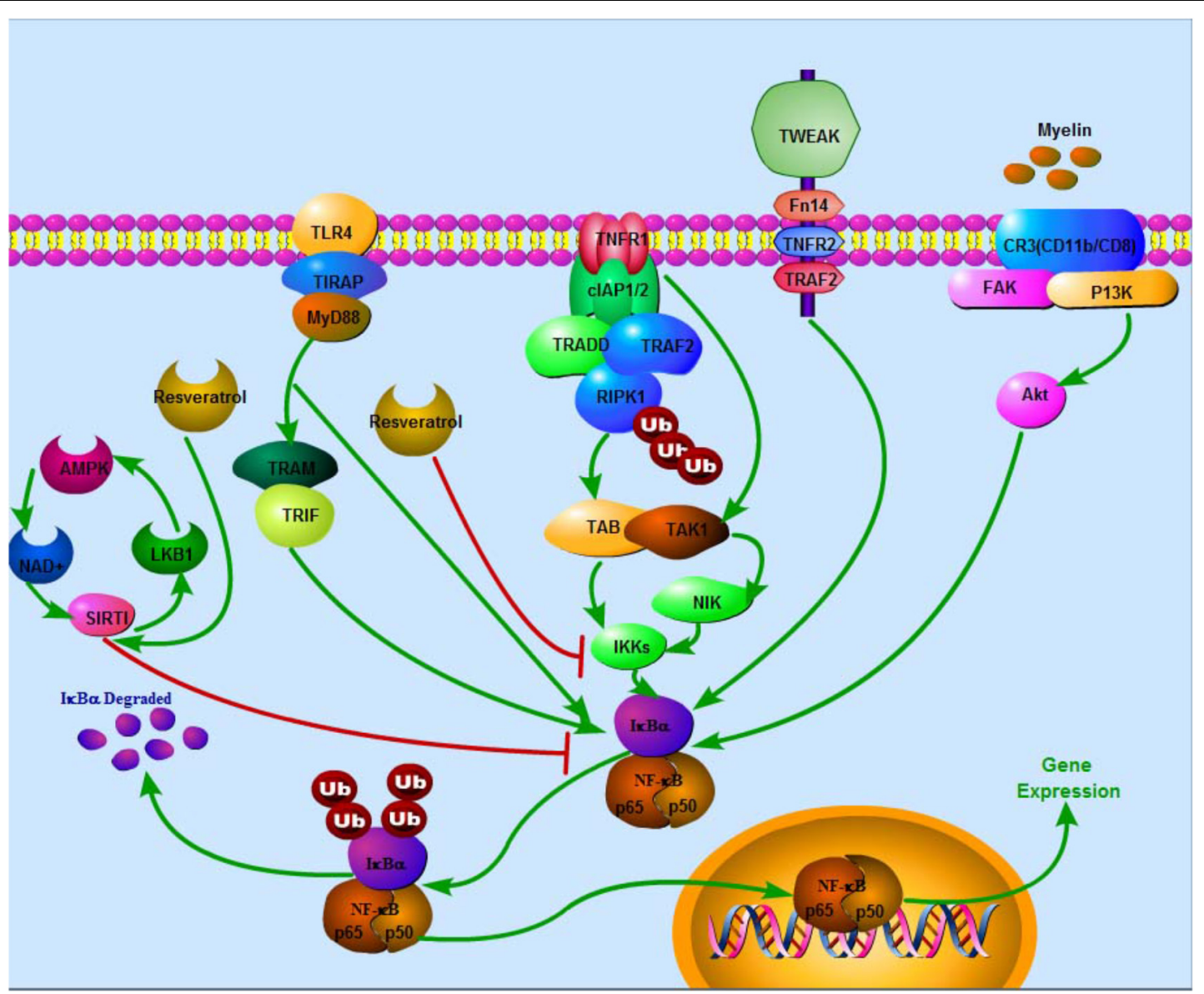

FIGURE 1 | Negative effects of resveratrol on NF-KB via several pathways in SCI. In TNFR1 apoptotic pathway, Ub chains conjugated with RIPK1 function as scaffolds in the recruitment and activation of TAK1-binding protein 2/3-TAK1 complex and inhibition of IKK complex (NEMO-IKKa-IKKb), subsequently triggering off the classical NF-кB signaling pathways that collectively promote transcription of genes, which prevents cell death and sustains inflammation. In MyD88-dependent pathway, TLR recruits toll-interleukin 1 receptor domain containing adaptor protein at the cell membrane, subsequently facilitating recruitment of MyD88, which in

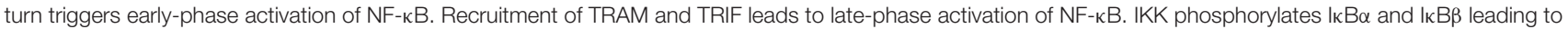

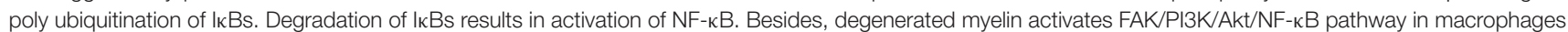

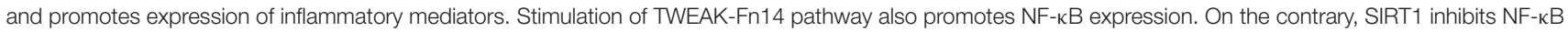
activation. Eventually, NF-кB enters the nucleus to activate target gene expression. Resveratrol potentially enhances SIRT1 and AMPK expressions. AMPK activation increases $\mathrm{NAD}+\mathrm{NADH}$ ratio and triggers its downstream whereas SIRT1 acts as an anti-inflammatory NAD+-dependent deacetylating enzyme via direct deacetylation of subunit of NF-kB such as p65, SIRT1 directly interacts with RelA/p65. Also, resveratrol suppresses IKK activity.

\section{RESVERATROL'S STIMULATION OF SCI AMELIORATION IS CORRELATED TO NF- $K B$ SIGNALING PATHWAY INHIBITION}

Though resveratrol has multiple beneficial health effects such as anti-inflammation and anti-apoptosis, some of these effects on SCI protection still remain unclear. Resveratrol significantly exerts effect on preserving structure and morphology of damaged tissues, protecting neurons from traumatic injury-induced apoptosis and promoting locomotive activity of hindlimb motor neurons in rats following SCI, which is possibly related to its pleiotropic effects including anti-oxidation, antiinflammation and anti-apoptosis. Resveratrol improves recovery of injured tissues in spinal cord via mediating participatory cytokines. Regarding anti-oxidation, resveratrol can reversely increase superoxide dismutase and decrease malondialdehyde to inhibit oxidation in SCI. Thus, resveratrol can potentially accelerate scavenging and protect cellular structure from damage to inhibit overproduction of free radicals. Concerning anti-inflammation, resveratrol can potentially curtail injuryinduced myeloperoxidase and other inflammatory factors such as IL-10 and TNF- $\alpha$ and relieve neutrophil infiltration to inhibit inflammation cascade. On the subject of anti-apoptosis, resveratrol could elevate expression of $\mathrm{Bcl}-2$, the anti-apoptotic substrate while inhibiting Bax and caspase-3, which attenuates triggering of apoptosis and reducing neuronal death (Liu et al., 2011).

Also, resveratrol could mediate SIRT1-AMPK signaling pathway to regulate autophagy and apoptosis that possibly plays a neuroprotective role in SCI. Resveratrol was found to 
enhance SIRT1 and AMPK expressions. Apoptotic expression is significantly suppressed by resveratrol on protein and mRNA level, which could possibly be related to the up-regulation of SIRT1/AMPK signaling pathway in the wake of SCI. Both SIRT1 and AMPK are crucial substrates in mediating autophagy (Zhao et al., 2017). AMPK activation increases NAD+/NADH ratio and triggers its downstream whereas SIRT1 acts as an antiinflammatory NAD+-dependent deacetylating enzyme via direct deacetylation of subunit of NF- $\kappa \mathrm{B}$ such as p65 (Yeung et al., 2004; Yang et al., 2012). SIRT1 directly interacts with RelA/p65 via deacetylation of RelA/p65 on lysine 310, a site crucial for NF- $\kappa \mathrm{B}$ transcriptional activity, to inhibit NF- $\kappa \mathrm{B}$ transcription. Employment of resveratrol potentiates SIRT1 protein on CIAP-2 gene, an effect that possibly correlates with liberating cIAP2 gene from regulation of $\mathrm{NF}-\kappa \mathrm{B}$ and sensitizing cells to TNF $\alpha$-induced apoptosis (Yeung et al., 2004). Besides, SIRT1 can potentially inversely activate AMPK or induce phosphorylation of peroxisome proliferators activated receptor- $\gamma$ coactivator- $1 \alpha$, thereby inhibiting RelA/p65-mediated NF- $\mathrm{B}$ signaling. AMPK has been evinced to be a negative regulator of NF- $\kappa \mathrm{B}$ signaling and is involved in inflammatory response in macrophages (Racioppi et al., 2012; O’Neill and Hardie, 2013). These negative effects by SIRT1-AMPK signaling pathway on NF-кB activity leads to enhanced IL-12 production and anti-inflammation (Liu et al., 2016).

There is the possibility of resveratrol inhibiting NF- $\kappa \mathrm{B}$ activity via SIRT1-AMPK signaling pathway to exert its beneficial effects on improving SCI. Hence, SIRT1-AMPK signaling pathway can be a possible bridge connecting autophagy and inflammation. Studies have indicated polydatin, a glucoside of resveratrol, to possess potent antioxidative effects. It has the potentiality of partly solving the problem of poor viability of transplanted bone marrow stem cells (BMSCs), which limits therapeutic efficacy. Thus, polydatin with BMSCs could possibly improve therapeutic effect of SCI (Chen et al., 2016). Resveratrol attenuates SCI-induced inflammatory damage in rats' lungs, which was accompanied by curtailment of pro-inflammatory factors, up-regulation of SIRT1 and antiinflammatory cytokines as well as suppression of NF-кB activity (Liu et al., 2015). Resveratrol was also demonstrated

\section{REFERENCES}

Ahn, K. S., and Aggarwal, B. B. (2005). Transcription factor NF-кB: a sensor for smoke and stress signals. Ann. N. Y. Acad. Sci. 1056, 218-233. doi: 10.1196/ annals. 1352.026

Annabi, B., Lord-Dufour, S., Vézina, A., and Béliveau, R. (2012). Resveratrol targeting of carcinogen-induced brain endothelial cell inflammation biomarkers MMP-9 and COX-2 is Sirt1-independent. Drug Target Insights 6, 1-11. doi: 10.4137/DTI.S9442

Arias, N., Picó, C., Teresa Macarulla, M., Oliver, P., Miranda, J., Palou, A., et al. (2017). A combination of resveratrol and quercetin induces browning in white adipose tissue of rats fed an obesogenic diet. Obesity 25, 111-121. doi: 10.1002/ oby. 21706

Bareyre, F. M., and Schwab, M. E. (2003). Inflammation, degeneration and regeneration in the injured spinal cord: insights from DNA microarrays. Trends Neurosci. 26, 555-563. doi: 10.1016/j.tins.2003.08.004 to exert some effect on enervated sub-lesional bone loss that is associated with repressed oxidative stress, curtailed inflammation, depressed peroxisome proliferators-activated receptor $\gamma$ signaling and restored $\mathrm{Wnt} / \beta$-catenin and insulinlike growth factors-1 signaling in SCI rats (Wang et al., 2013).

\section{CONCLUSION}

Nuclear factor kappa-light-chain-enhancer of activated B cells signaling pathway plays a crucial role in exhibition of inflammation, promotion of damage caused by free radicals and lipid peroxidation as well as facilitation of apoptosis and axonal demyelination in SCI. Resveratrol has been studied in the treatment of various diseases in different organs via NF$\kappa \mathrm{B}$ signaling pathway. Beneficial effect of resveratrol in SCI is explicated as evidenced previously. Thus, we hypothesize resveratrol to potentially improve SCI by inhibiting NF-кB signaling pathway. With that said, more direct researches are needed to explore interior mechanisms between resveratrol and NF- $\kappa \mathrm{B}$ signaling pathway following SCI, which in turn could support promising value of resveratrol in SCI therapy. Finally, appropriate and precise phase at which resveratrol can be employed needs to be elucidated.

\section{AUTHOR CONTRIBUTIONS}

XL participated in the study design. LX, JZ, SZ, and XL prepared the first draft of the manuscript. LX, BB, and XL participated in revision of the manuscript and approved the final paper.

\section{FUNDING}

The Natural Science Foundation of Zhejiang Province (No. LY15H170001) and the Public Technology Applied Research Projects Foundation of Shaoxing City (No. 2015B70040) supported this work.

Beattie, M. S., Hermann, G. E., Rogers, R. C., and Bresnahan, J. C. (2002). Cell death in models of spinal cord injury. Prog. Brain Res. 137, 37-47. doi: 10.1016/S00796123(02)37006-7

Bennett, B. T., Mohamed, J. S., and Always, S. E. (2013). Effects of resveratrol on the recovery of muscle mass following disuse in the plantaris muscle of aged rats. PLoS One 8:e83518. doi: 10.1371/journal.pone. 0083518

Bhat, K. P., and Pezzuto, J. M. (2002). Cancer chemopreventive activity of resveratrol. Ann. N. Y. Acad. Sci. 957, 210-229. doi: 10.1111/j.1749-6632.2002. tb02918.x

Bishayee, A., Waghray, A., Barnes, K. F., Mbimba, T., Bhatia, D., Chatterjee, M., et al. (2010). Suppression of the inflammatory cascade is implicated in resveratrol chemoprevention of experimental hepatocarcinogenesis. Pharm. Res. 27, 1080-1091. doi: 10.1007/s11095-010-0144-4

Blank, T., and Prinz, M. (2014). NF- $\kappa$ B signaling regulates myelination in the CNS. Front. Mol. Neurosci. 7:47. doi: 10.3389/fnmol.2014.00047 
Bonsack, F., Alleyne, C. H. Jr., and Sukumari-Ramesh, S. (2017). Resveratrol attenuates neurodegeneration and improves neurological outcomes after intracerebral hemorrhage in mice. Front. Cell. Neurosci. 11:228. doi: 10.3389/ fncel.2017.00228

Brasier, A. R. (2006). The NF-kappaB regulatory network. Cardiovasc. Toxicol. 6, 111-130. doi: 10.1385/CT:6:2:111

Buhrmann, C., Busch, F., Shayan, P., and Shakibaei, M. (2014). Sirtuin-1 (SIRT1) is required for promoting chondrogenic differentiation of mesenchymal stem cells. J. Biol. Chem. 289, 22048-22062. doi: 10.1074/jbc.M114.568790

Buhrmann, C., Yazdi, M., Popper, B., Shayan, P., Goel, A., Aggarwal, B. B., et al. (2018). Resveratrol chemosensitizes TNF- $\beta$-induced survival of 5-FU-treated colorectal cancer cells. Nutrients 10:E888. doi: 10.3390/nu10070888

Chai, R., Fu, H., Zheng, Z., Liu, T., Ji, S., and Li, G. (2017). Resveratrol inhibits proliferation and migration through SIRT1 mediated post-translational modification of PI3K/AKT signaling in hepatocellular carcinoma cells. Mol. Med. Rep. 16, 8037-8044. doi: 10.3892/mmr.2017.7612

Chávez, E., Reyes-gordillo, K., Segovia, J., Shibayama, M., Tsutsumi, V., Vergara, P., et al. (2008). Resveratrol prevents fibrosis, NF-kappaB activation and TGF-beta increases induced by chronic CCl4 treatment in rats. J. Appl. Toxicol. 28, 35-43. doi: $10.1002 /$ jat.1249

Chen, M., Hou, Y., and Lin, D. (2016). Polydatin protects bone marrow stem cells against oxidative injury: involvement of Nrf 2/ARE pathways. Stem Cells Int. 2016:9394150. doi: 10.1155/2016/9394150

Cheng, L., Yan, B., Chen, K., Jiang, Z., Zhou, C., Cao, J., et al. (2018). Resveratrolinduced downregulation of NAF-1 Enhances the sensitivity of pancreatic cancer cells to gemcitabine via the ROS/Nrf2 signaling pathways. Oxid. Med. Cell. Longev. 2018:9482018. doi: 10.1155/2018/9482018

Cheng, Z., Zhu, W., Cao, K., Wu, F., Li, J., Wang, G., et al. (2016). Antiinflammatory mechanism of neural stem cell transplantation in spinal cord injury. Int. J. Mol. Sci. 17:E1380. doi: 10.3390/ijms17091380

Chin, Y. T., Yang, S. H., Chang, T. C., Changou, C. A., Lai, H. Y., Fu, E., et al. (2015). Mechanisms of dihydrotestosterone action on resveratrol-induced antiproliferation in breast cancer cells with different ER $\alpha$ status. Oncotarget 6, 35866-35879. doi: 10.18632/oncotarget.5482

Church, J. S., Milich, L. M., Lerch, J. K., Popovich, P. G., and McTigue, D. M. (2017). E6020, a synthetic TLR4 agonist, accelerates myelin debris clearance, Schwann cell infiltration, and remyelination in the rat spinal cord. Glia 65, 883-899. doi: 10.1002/glia.23132

Cianciulli, A., Calvello, R., Cavallo, P., Dragone, T., Carofiglio, V., and Panaro, M. A. (2012). Modulation of NF- $\kappa B$ activation by resveratrol in LPS treated human intestinal cells results in downregulation of PGE2 production and COX-2 expression. Toxicol. In vitro 26, 1122-1128. doi: 10.1016/j.tiv.2012. 06.015

Dai, H., Deng, H. B., Wang, Y. H., and Guo, J. J. (2018). Resveratrol inhibits the growth of gastric cancer via the $\mathrm{Wnt} / \beta$-catenin pathway. Oncol. Lett. 16, 1579-1583. doi: 10.3892/ol.2018.8772

Dondelinger, Y., Aguileta, M. A., Goossens, V., Dubuisson, C., Grootjans, S., Dejardin, E., et al. (2013). RIPK3 contributes to TNFR1-mediated RIPK1 kinase-dependent apoptosis in conditions of cIAP1/2 depletion or TAK1 kinase inhibition. Cell Death Differ. 20, 1381-1392. doi: 10.1038/cdd.2013.94

Donnelly, D. J., and Popovich, P. G. (2008). Inflammation and its role in neuroprotection, axonal regeneration and functional recovery after spinal cord injury. Exp. Neurol. 209, 378-388. doi: 10.1016/j.expneurol.2007.06.009

Emmanouil, M., Taoufik, E., Tseveleki, V., Vamvakas, S. S., and Probert, L. (2011). A role for neuronal NF- $\mathrm{BB}$ in suppressing neuroinflammation and promoting neuroprotection in the CNS. Adv. Exp. Med. Biol. 691, 575-581. doi: 10.1007/ 978-1-4419-6612-4_60

Finnell, J. E., Lombard, C. M., Melson, M. N., Singh, N. P., Nagarkatti, M., Nagarkatti, P., et al. (2016). The protective effects of resveratrol on social stressinduced cytokine release and depressive-like behavior. Brain Behav. Immun. 59, 147-157. doi: 10.1016/j.bbi.2016.08.019

Gloire, G., Legrand-Poels, S., and Piette, J. (2006). NF-kappaB activation by reactive oxygen species: fifteen years later. Biochem. Pharmacol. 72, 1493-1505. doi: 10.1016/j.bcp.2006.04.011

Guadagno, J., Xu, X., Karajgikar, M., Brown, A., and Cregan, S. P. (2013). Microglia-derived TNF $\alpha$ induces apoptosis in neural precursor cells via transcriptional activation of the Bcl-2 family member Puma. Cell Death Dis. 4:e538. doi: 10.1038/cddis.2013.59
Harper, C. E., Patel, B. B., Wang, J., Arabshahi, A., Eltoum, I. A., and Lamartiniere, C. A. (2007). Resveratrol suppresses prostate cancer progression in transgenic mice. Carcinogenesis 28, 1946-1953. doi: 10.1093/carcin/bgm144

Heise, N., De Silva, N. S., Silva, K., Carette, A., Simonetti, G., Pasparakis, M., et al. (2014). Germinal center B cell maintenance and differentiation are controlled by distinct NF-кB transcription factor subunits. J. Exp. Med. 211, 2103-2118. doi: $10.1084 /$ jem.20132613

Huang, T., Gao, D., Jiang, X., Hu, S., Zhang, L., and Fei, Z. (2014). Resveratrol inhibits oxygen-glucose deprivation-induced MMP-3 expression and cell apoptosis in primary cortical cells via the NF-кB pathway. Mol. Med. Rep. 10, 1065-1071. doi: 10.3892/mmr.2014.2239

Jamme, I., Petit, E., Divoux, D., Gerbi, A., Maixent, J. M., and Nouvelot, A. (1995). Modulation of mouse cerebral $\mathrm{Na}+, \mathrm{K}(+)$-ATPase activity by oxygen free radicals. Neuroreport 7, 333-337.

Jia, Z., Zhu, H., Li, J., Wang, X., Misra, H., and Li, Y. (2012). Oxidative stress in spinal cord injury and antioxidant-based intervention. Spinal Cord 50, 264-274. doi: 10.1038/sc.2011.111

Jiang, W., Li, M., He, F., Yao, W., Bian, Z., Wang, X., et al. (2016). Protective effects of asiatic acid against spinal cord injury-induced acute lung injury in rats. Inflammation 39, 1853-1861. doi: 10.1007/s10753-016-0414-3

Kamata, H., Honda, S., Maeda, S., Chang, L., Hirata, H., and Karin, M. (2005). Reactive oxygen species promote TNFalpha-induced death and sustained JNK activation by inhibiting MAP kinase phosphatases. Cell 120, 649-661. doi: 10.1016/j.cell.2004.12.041

Kaminskyy, V. O., and Zhivotovsky, B. (2014). Free radicals in cross talk between autophagy and apoptosis. Antioxid. Redox Signal. 21, 86-102. doi: 10.1089/ars. 2013.5746

Kawai, T., and Akira, S. (2010). The role of pattern-recognition receptors in innate immunity: update on Toll-like receptors. Nat. Immunol. 11, 373-384. doi: $10.1038 /$ ni.1863

Kim, A., Nam, Y. J., and Lee, C. S. (2017). Taxifolin reduces the cholesterol oxidation product-induced neuronal apoptosis by suppressing the Akt and NFКB activation-mediated cell death. Brain Res. Bull. 134, 63-71. doi: 10.1016/j. brainresbull.2017.07.008

Kondylis, V., Kumari, S., Vlantis, K., and Pasparakis, M. (2017). The interplay of IKK, NF- $\kappa$ B and RIPK1 signaling in the regulation of cell death, tissue homeostasis and inflammation. Immunol. Rev. 277, 113-127. doi: 10.1111/imr. 12550

Kong, G., Huang, Z., Ji, W., Wang, X., Liu, J., Wu, X., et al. (2017). The ketone metabolite $\beta$-hydroxybutyrate attenuates oxidative stress in spinal cord injury by suppression of class I histone deacetylases. J. Neurotrauma 34, 2645-2655. doi: $10.1089 /$ neu.2017.5192

Kopper, T. J., and Gensel, J. C. (2017). Myelin as an inflammatory mediator: myelin interactions with complement, macrophages, and microglia in spinal cord injury. J. Neurosci. Res. 96, 969-977. doi: 10.1002/jnr.24114

Kulkarni, S. S., and Cantó, C. (2015). The molecular targets of resveratrol. Biochim. Biophys. Acta 1852, 1114-1123. doi: 10.1016/j.bbadis.2014.10.005

Kumar, A., Dhar, S., Rimando, A. M., Lage, J. M., Lewin, J. R., Zhang, X., et al. (2015). Epigenetic potential of resveratrol and analogs in preclinical models of prostate cancer. Ann. N. Y. Acad. Sci. 1348, 1-9. doi: 10.1111/nyas.12817

Kundu, J. K., Shin, Y. K., and Surh, Y. J. (2006). Resveratrol modulates phorbol ester-induced pro-inflammatory signal transduction pathways in mouse skin in vivo: NF-kappaB and AP-1 as prime targets. Biochem. Pharmacol. 72, 1506-1515. doi: 10.1016/j.bcp.2006.08.005

Lai, X., Cao, M., Song, X., Jia, R., Zou, Y., Li, L., et al. (2017). Resveratrol promotes recovery of immune function of immunosuppressive mice by activating JNK/NF-кB pathway in splenic lymphocytes. Can. J. Physiol. Pharmacol. 95, 763-767. doi: 10.1139/cjpp-2016-0404

Langcake, P., and Pryce, R. J. (1976). The production of resveratrol by Vitis vinifera and other members of the Vitaceae as a response to infection or injury. Physiol. Mol. Plant Pathol. 9, 77-86. doi: 10.1016/0048-4059(76)90077-1

Lee, B. B., Cripps, R. A., Fitzharris, M., and Wing, P. C. (2014). The global map for traumatic spinal cord injury epidemiology: update 2011, global incidence rate. Spinal Cord 52, 110-116. doi: 10.1038/sc.2012.158

Lee, J. Y., Kim, H. S., Choi, H. Y., Oh, T. H., Ju, B. G., and Yune, T. Y. (2012). Valproic acid attenuates blood-spinal cord barrier disruption by inhibiting matrix metalloprotease- 9 activity and improves functional recovery after spinal cord injury. J. Neurochem. 121, 818-829. doi: 10.1111/j.1471-4159.2012.07731.x 
Li, H., Jia, Z., Li, A., Jenkins, G., Yang, X., Hu, J., et al. (2013). Resveratrol repressed viability of U251 cells by miR-21 inhibiting of NF-кB pathway. Mol. Cell Biochem. 382, 137-143. doi: 10.1007/s11010-013-1728-1

Li, J., Li, L., Wang, S., Zhang, C., Zheng, L., Jia, Y., et al. (2018). Resveratrol alleviates inflammatory responses and oxidative stress in rat kidney ischemiareperfusion injury and $\mathrm{H}_{2} \mathrm{O}_{2}$-Induced NRK-52E Cells via the Nrf2/TLR4/NFкB Pathway. Cell Physiol. Biochem. 45, 1677-1689. doi: 10.1159/000487735

Liu, C., Shi, Z., Fan, L., Zhang, C., Wang, K., and Wang, B. (2011). Resveratrol improves neuron protection and functional recovery in rat model of spinal cord injury. Brain Res. 1374, 100-109. doi: 10.1016/j.brainres.2010.11.061

Liu, C. W., Sung, H. C., Lin, S. R., Wu, C. W., Lee, C. W., Lee, I. T., et al. (2017). Resveratrol attenuates ICAM-1 expression and monocyte adhesiveness to TNF- $\alpha$-treated endothelial cells: evidence for an anti-inflammatory cascade mediated by the miR-221/222/AMPK/p38/NF-kB pathway. Sci. Rep. 7:44689. doi: $10.1038 /$ srep 44689

Liu, J., Yi, L., Xiang, Z., Zhong, J., Zhang, H., and Sun, T. (2015). Resveratrol attenuates spinal cord injury-induced inflammatory damage in rat lungs. Int. J. Clin. Exp. Pathol. 8, 1237-1246.

Liu, X., Wang, N., Zhu, Y., Yang, Y., Chen, X., Fan, S., et al. (2016). Inhibition of extracellular calcium influx results in enhanced IL-12 production in LPStreated murine macrophages by downregulation of the CaMKK $\beta$-AMPKSIRT1 signaling pathway. Mediators Inflamm. 2016, 1-15. doi: 10.1155/2016/ 7432845

Luo, G., Huang, B., Qiu, X., Xiao, L., Wang, N., Gao, Q., et al. (2017). Resveratrol attenuates excessive ethanol exposure induced insulin resistance in rats via improving $\mathrm{NAD}(+)$ /NADH ratio. Mol. Nutr. Food Res. 61:1700087. doi: $10.1002 / \mathrm{mnfr} .201700087$

Ma, L., Zhao, Y., Wang, R., Chen, T., Li, W., Nan, Y., et al. (2015). 3,5,4'-Tri-O-acetylresveratrol attenuates Lipopolysaccharide-induced acute respiratory distress syndrome via MAPK/SIRT1 Pathway. Mediators Inflamm. 2015:143074. doi: 10.1155/2015/143074

Mantovani, A., Sica, A., Sozzani, S., Allavena, P., Vecchi, A., and Locati, M. (2004). The chemokine system in diverse forms of macrophage activation and polarization. Trends Immunol. 25, 677-686. doi: 10.1016/j.it.2004.09.015

Moussa, C., Hebron, M., Huang, X., Ahn, J., Rissman, R. A., Aisen, P. S., et al. (2017). Resveratrol regulates neuro-inflammation and induces adaptive immunity in Alzheimer's disease. J. Neuroinflammation 14:1. doi: 10.1186/ s12974-016-0779-0

Nalagoni, C. S. R., and Karnati, P. R. (2016). Protective effect of resveratrol against neuronal damage through oxidative stress in cerebral hemisphere of aluminum and fluoride treated rats. Interdiscip. Toxicol. 9, 78-82. doi: 10.1515/intox-20160009

Ni, H., Jin, W., Zhu, T., Wang, J., Yuan, B., Jiang, J., et al. (2015). Curcumin modulates TLR4/NF- $\mathrm{KB}$ inflammatory signaling pathway following traumatic spinal cord injury in rats. J. Spinal Cord Med. 38, 199-206. doi: 10.1179/ 2045772313Y.0000000179

O’Dea, E. L., Barken, D., Peralta, R. Q., Tran, K. T., Werner, S. L., Kearns, J. D., et al. (2007). A homeostatic model of IkappaB metabolism to control constitutive NF-kappaB activity. Mol. Syst. Biol. 3:111.

O'Neill, L. A., and Hardie, D. G. (2013). Metabolism of inflammation limited by AMPK and pseudo-starvation. Nature 493, 346-355. doi: 10.1038/nature11862

Pan, X., Chen, J., Wang, W., Chen, L., Wang, L., Ma, Q., et al. (2016). Resveratrolinduced antinociception is involved in calcium channels and calcium/caffeinesensitive pools. Oncotarget 8, 9399-9409.

Pei, J. P., Fan, L. H., Nan, K., Li, J., Dang, X. Q., and Wang, K. Z. (2017). HSYA alleviates secondary neuronal death through attenuating oxidative stress, inflammatory response, and neural apoptosis in SD rat spinal cord compression injury. J. Neuroinflammation 14:97. doi: 10.1186/s12974-017-0870-1

Poschner, S., Maier-Salamon, A., Zehl, M., Wackerlig, J., Dobusch, D., Meshcheryakova, A., et al. (2018). Resveratrol inhibits key steps of steroid metabolism in a human estrogen-receptor positive breast cancer model: impact on cellular proliferation. Front. Pharmacol. 9:742. doi: 10.3389/fphar.2018. 00742

Racioppi, L., Noeldner, P. K., Lin, F., Arvai, S., and Means, A. R. (2012). Calcium/calmodulin-dependent protein kinase kinase 2 regulates macrophagemediated inflammatory responses. J. Biol. Chem. 287, 11579-11591. doi: 10. 1074/jbc.M111.336032
Renaud, S., and de Lorgeril, M. (1992). Wine, alcohol, platelets, and the French paradox for coronary artery disease. Lancet 339, 1523-1526. doi: 10.1016/01406736(92)91277-F

Riba, A., Deres, L., Sumegi, B., Toth, K., Szabados, E., and Halmosi, R. (2017). Cardioprotective effect of resveratrol in a postinfarction heart failure model. Oxid. Med. Cell. Longev. 2017:6819281. doi: 10.1155/2017/6819281

Rowland, J. W., Hawryluk, G. W., Kwon, B., and Fehlings, M. G. (2008). Current status of acute spinal cord injury pathophysiology and emerging therapies: promise on the horizon. Neurosurg. Focus 25:E2. doi: 10.3171/FOC.2008. 25.11.E2

Sakata, Y., Zhuang, H., Kwansa, H., Koehler, R. C., and Doré, S. (2010). Resveratrol protects against experimental stroke: putative neuroprotective role of heme oxygenase 1. Exp. Neurol. 224, 325-329. doi: 10.1016/j.expneurol.2010.03.032

Saluzzo, J., Hallman, K. M., Aleck, K., Dwyer, B., Quigley, M., Mladenovik, V., et al. (2016). The regulation of tumor suppressor protein, p53, and estrogen receptor $(\mathrm{ER} \alpha)$ by resveratrol in breast cancer cells. Genes Cancer 7, 414-425.

Schanne, F. A., Kane, A. B., Young, E. E., and Farber, J. L. (1979). Calcium dependence of toxic cell death: a final common pathway. Science 206, 700-702. doi: $10.1126 /$ science. 386513

Silva, N. A., Sousa, N., Reis, R. L., and Salgado, A. J. (2014). From basics to clinical: a comprehensive review on spinal cord injury. Prog. Neurobiol. 114, 25-57. doi: 10.1016/j.pneurobio.2013.11.002

Sun, X., Wang, X., Chen, T., Li, T., Cao, K., Lu, A., et al. (2010). Myelin activates FAK/Akt/NF-kappaB pathways and provokes CR3-dependent inflammatory response in murine system. PLoS One 5:e9380. doi: 10.1371/journal.pone. 0009380

Takahashi, N., Vereecke, L., Bertrand, M. J., Duprez, L., Berger, S. B., Divert, T., et al. (2014). RIPK1 ensures intestinal homeostasis by protecting the epithelium against apoptosis. Nature 513, 95-99. doi: 10.1038/nature13706

Takaoka, M. (1939). Resveratrol, a new phenolic compound from Veratrum grandiflorum. J. Chem. Soc. Japan 60, 1090-1100.

Tino, A. B., Chitcholtan, K., Sykes, P. H., and Garrill, A. (2016). Resveratrol and acetyl-resveratrol modulate activity of VEGF and IL-8 in ovarian cancer cell aggregates via attenuation of the NF- $\mathrm{KB}$ protein. J. Ovarian Res. 9:84.

Tsai, M. H., Hsu, L. F., Lee, C. W., Chiang, Y. C., Lee, M. H., How, J. M., et al. (2017). Resveratrol inhibits urban particulate matter-induced COX-2/PGE2 release in human fibroblast-like synoviocytes via the inhibition of activation of NADPH oxidase/ROS/NF-кB. Int. J. Biochem. Cell Biol. 88, 113-123. doi: 10.1016/j.biocel.2017.05.015

Tsang, S. W., Guan, Y. F., Wang, J., Bian, Z. X., and Zhang, H. J. (2016). Inhibition of pancreatic oxidative damage by stilbene derivative dihydro-resveratrol: implication for treatment of acute pancreatitis. Sci. Rep. 6:22859. doi: 10.1038/ srep22859

Vanlangenakker, N., Vanden Berghe, T., Bogaert, P., Laukens, B., Zobel, K., Deshayes, K., et al. (2011). cIAP1 and TAK1 protect cells from TNFinduced necrosis by preventing RIP1/RIP3-dependent reactive oxygen species production. Cell Death Differ. 18, 656-665. doi: 10.1038/cdd.2010.138

Wang, G., Dai, F., Yu, K., Jia, Z., Zhang, A., Huang, Q., et al. (2015). Resveratrol inhibits glioma cell growth via targeting oncogenic microRNAs and multiple signaling pathways. Int. J. Oncol. 46, 1739-1747. doi: 10.3892/ijo.2015.2863

Wang, H. D., Shi, Y. M., Li, L., Guo, J. D., Zhang, Y. P., and Hou, S. X. (2013). Treatment with resveratrol attenuates sublesional bone loss in spinal cord-injured rats. Br. J. Pharmacol. 170, 796-806. doi: 10.1111/bph.12301

Wang, N., Mao, L., Yang, L., Zou, J., Liu, K., Liu, M., et al. (2017). Resveratrol protects against early polymicrobial sepsis-induced acute kidney injury through inhibiting endoplasmic reticulum stress-activated NF-кB pathway. Oncotarget 8, 36449-36461. doi: 10.18632/oncotarget.16860

Wei, Y., Jia, J., Jin, X., Tong, W., and Tian, H. (2018). Resveratrol ameliorates inflammatory damage and protects against osteoarthritis in a rat model of osteoarthritis. Mol. Med. Rep. 17, 1493-1498. doi: 10.3892/mmr.2017.8036

Wood, J. G., Rogina, B., Lavu, S., Howitz, K., Helfand, S. L., and Tatar, M. (2004). Sirtuin activators mimic caloric restriction and delay ageing in metazoans. Nature 430, 686-689. doi: 10.1038/nature02789

Xia, N., Daiber, A., Habermeier, A., Closs, E. I., Thum, T., Spanier, G., et al. (2010). Resveratrol reverses endothelial nitric-oxide synthase uncoupling in apolipoprotein E knockout mice. J. Pharmacol. Exp. Ther. 335, 149-154. doi: 10.1124/jpet.110.168724 
$\mathrm{Xu}$, J., He, J., He, H., Peng, R., and Xi, J. (2016). TWEAK-Fn14 influences neurogenesis status via modulating NF- $\kappa \mathrm{B}$ in mice with spinal cord injury. Mol. Neurobiol. 54, 7497-7506. doi: 10.1007/s12035-016-0248-x

Xu, W., Chi, L., Xu, R., Ke, Y., Luo, C., Cai, J., et al. (2005). Increased production of reactive oxygen species contributes to motor neuron death in a compression mouse model of spinal cord injury. Spinal Cord 43, 204-213. doi: 10.1038/sj.sc. 3101674

Yang, H., Zhang, W., Pan, H., Feldser, H. G., Lainez, E., Miller, C., et al. (2012). SIRT1 activators suppress inflammatory responses through promotion of p65 deacetylation and inhibition of NF-кB activity. PLoS One 7:e46364. doi: 10. 1371/journal.pone.0046364

Yeung, F., Hoberg, J. E., Ramsey, C. S., Keller, M. D., Jones, D. R., and Frye, R. A. (2004). Modulation of NF-kappaB-dependent transcription and cell survival by the SIRT1 deacetylase. EMBO J. 23, 2369-2380. doi: 10.1038/sj.emboj. 7600244

Zandi, E., Chen, Y., and Karin, M. (1998). Direct phosphorylation of IkappaB by IKKalpha and IKKbeta: discrimination between free and NF-kappaB-bound substrate. Science 281, 1360-1363. doi: 10.1126/science.281.5381.1360

Zare Javid, A., Hormoznejad, R., Yousefimanesh, H. A., Zakerkish, M., Haghighi-Zadeh, M. H., and Dehghan, P. (2017). The impact of resveratrol supplementation on blood glucose, insulin, insulin resistance, triglyceride, and periodontal markers in type 2 diabetic patients with chronic periodontitis. Phytother. Res. 31, 108-114. doi: 10.1002/ptr.5737

Zhang, Q., Wang, J., Gu, Z., Zhang, Q., and Zheng, H. (2016). Effect of lycopene on the blood-spinal cord barrier after spinal cord injury in mice. Biosci. Trends 10, 288-293. doi: 10.5582/bst.2016.01062

Zhang, X., Wu, Q., Zhang, Q., Lu, Y., Liu, J., Li, W., et al. (2017). Resveratrol attenuates early brain injury after experimental subarachnoid hemorrhage via inhibition of NLRP3 inflammasome activation. Front. Neurosci. 11:611. doi: $10.3389 /$ fnins.2017.00611
Zhang, Z. H., Yu, L. J., Hui, X. C., Wu, Z. Z., Yin, K. L., Yang, H., et al. (2014). Hydroxy-safflor yellow A attenuates A $\beta 1-42$ - induced inflammation by modulating the JAK2/STAT3/NF-кB pathway. Brain Res. 1563, 72-80. doi: 10.1016/j.brainres.2014.03.036

Zhao, H., Chen, S., Gao, K., Zhou, Z., Wang, C., Shen, Z., et al. (2017). Resveratrol protects against spinal cord injury by activating autophagy and inhibiting apoptosis mediated by the SIRT1/AMPK signaling pathway. Neuroscience 348, 241-251. doi: 10.1016/j.neuroscience.2017.02.027

Zhao, Y., Song, W., Wang, Z., Wang, Z., Jin, X., Xu, J., et al. (2018). Resveratrol attenuates testicular apoptosis in type 1 diabetic mice: role of Akt-mediated Nrf2 activation and p62-dependent Keap1 degradation. Redox Biol. 14, 609617. doi: 10.1016/j.redox.2017.11.007

Zheng, X., Jia, B., Song, X., Kong, Q. Y., Wu, M. L., Qiu, Z. W., et al. (2018). Preventive potential of resveratrol in carcinogen-induced rat thyroid tumorigenesis. Nutrients 10:E279. doi: 10.3390/nu10030279

Zhou, W., Yuan, T., Gao, Y., Yin, P., Liu, W., Pan, C., et al. (2017). IL-1 $\beta$-induces NF-кB and upregulates microRNA-372 to inhibit spinal cord injury recovery. J. Neurophysiol. 117, 2282-2291. doi: 10.1152/jn.00936.2016

Conflict of Interest Statement: The authors declare that the research was conducted in the absence of any commercial or financial relationships that could be construed as a potential conflict of interest.

Copyright (C) $2018 \mathrm{Xu}$, Botchway, Zhang, Zhou and Liu. This is an open-access article distributed under the terms of the Creative Commons Attribution License (CC BY). The use, distribution or reproduction in other forums is permitted, provided the original author(s) and the copyright owner(s) are credited and that the original publication in this journal is cited, in accordance with accepted academic practice. No use, distribution or reproduction is permitted which does not comply with these terms. 